\title{
Bruno Kisch (1890-1966) zum Andenken
}

Bruno Kisch, während fast 25 Jahren Herausgeber unserer Zeitschrift, ist im Herbst 1966 verstorben. Er war als Physiologe mit bemerkenswertem klinischem interesse geradezu prädestiniert für diese Funktion dank seiner soliden und breiten naturwissen-schaftlichen Basis bei gediegener humanistisch-philosophischer Schulung. Für ihn selbst bedeutete die Redaktionstätigkeit an der «Cardiologia» keine grundlegende Veränderung, indem das neue Publikationsorgan aus der von Kisch selbst begründeten und redi-gierten «Zeitschrift für Kreislaufforschung» (1925-1935) heraus-gewachsen war. Es handelte sich um ihre Verpflanzung in einen neuen, ruhigen Grund und in adaequate Atmosphäre. In den fast 25 Jahren unter seiner Obhut hat sie sich erfreulich entwickelt und weitgehendes Interesse gefunden. Dankba $\Gamma$ anerkennen die Zeitschrift und ihre Leser die großen Verdienste des verstorbenen Herausgebers.

Der stiile, überaus fein veranlagte Forscher und Gelehrte wurde 1935 durch eines der ersten brutalen Pogrome jäh aufge-schreckt. Er war aufs tiefste erschüttert in seinem Glauben an seín Deutschland, das er über alles geliebt hat, jenes Deutschland, das er so anders gesehen hatte und wohl auch anders hatte sehen wollen, von dem er glaubte, es sei nach dem 1. Weltkrieg «unerhört geknechtet durch die Sieger». Schwerer noch denn als Ange-höriger der Verfolgten war er getroffen und erschüttert in diesem seinem Glauben an Deutschland.

Noch sehe ich ihn, aufgewühlt nicht durch Verlust von Hab und Gut und Stellung, sondern durch die Art und Weise, wie die Menschenwürde mit Füßen getreten wurde. Bitter klagte er: «Hät-ten Sie Solches mitansehen müssen, Sie würden auch an der Ret-tung des Geistes verzweifeln.» Und so war er gezwungen, die Wan-derung anzutreten, auferlegt seinem Volk, immer wieder, seit fünf-tausend Jahren.

Nicht ein Jahrzehnt war verstrichen, seit Kisch einer Festrede als Motto vorangesetzt hat: «Bildung schützt vor Fanatismus.»

In dieser Auseinandersetzung mit dem philosophischen Mate-rialismus, der Ende des letzten Jahrhunderts, weil bequem, simpli-stisch, erfolgzeitigend, manche Naturwissenschafter erfaßt hatte und tief in gewisse Gesellschaftsschichten eingedrungen war, klingt eigenartig eine tiefe Besorgnis durch, es könnten in Deutschland wissenschaftlich drapierte materialistische Irrlehren die Oberhand

Cardiologia, Vol. 49, No. 6 (1966)

23

318

Bruno Kisch (1890-1966) zum Andenken gewinnen. Kant wird beschworen, wenn er schreibt: «llch glaube, daß die unvergängliche Ideologie eines Kant uns eine genügende Gewähr dafür bietet, daß ein solches $\mathrm{S} \% \frac{1}{8}$ eben niemals wieder den Weg zum finsteren Aberglauben und zu einer mittelalterlichen geistigen Tätigkeit eröffnen kann.» 1 Es klingt, als habe er ver-sucht, der Barbarei einen Schild vorzuhalten, wohl zweifelnd, aber in hoffender Abwehr, auf einen guten Kern und auf den Sieg des Geistes, der Vernunft und der Humanität. Wie grausam sollten seine Befürchtungen übertroffen werden. 
Anläßlich seines 60. Geburtstages 2 haben wir auf Kisch's gro-ße Verdienste um die Verbreitung der Strophanthinterapie hin-gewiesen. Sie hat in Europa ihr hohes Ansehen bewahrt. Ihre Wiederentdeckung in USA steht noch immer bevor. Allerdings haben die hochwirksamen modernen Saliuretica und Carboanhydrasen-hemmer zurzeit das Interesse an dieser erstrangigen Herztherapie etwas in den Hintergrund gedrängt.

Kisch war ein Vertreter der Gruppe der Allround-Physiologen, die Biochemie, Physiologie und Pathophysiologie überblickend in ihren chemischen, graphischen und morphologischen Methoden. In der Bearbeitung weit ins Einzelne gehender Spezialprobleme war ihm der Gedanke an eine mögliche Nutzanwendung der Resul-tate fremd. So begann er 1937 die Serie der «Cardiologia» mit einem Aufsatz über Zwischenzacken im EKG, zwischen S und T sowie solchen zwischen P und Q. Nie hat Kisch selbst den Blick auf das Ganze verloren.

Der milde, konsequente und tapfere Forscher hat durch die Sorgfalt und Durchdachtheit seiner Arbeiten und nicht zuletzt durch sein freundlich-konziliantes und vermittelndes Wesen sich allgemeinster Beliebtheit erfreut. Nicht nur die «Cardiologia», auch die Herzforschung hat in ihm einen hervorragenden Vertreter verloren. Dank seiner auf den Menschenwert gerichteten umfassend philosophischen Einstellung waren in ihm Mensch und Forscher ungeteilt und seine Persönlichkeit von harmonischer Einheit.

Allen, die ihn kannten, wird er im besten Andenken bleiben.

W. Löffler, Zurich

1 Bruno Kisch: «NatuГwissenschaft und Weltanschauung*. Festrede anläß lich des 25jährigen Bestehens des Vereins für Natur- und Heimatkunde in Köln a. Rh., 1931, S. 61.

2 Vgl. «Würdigung zum 60. Geburtstag», Cardiologia, Vol. XVI, Fasc. 5/6 (1950). 